monográfico: Trasplante Renal. Experiencia del Hospital Clínico de Barcelona

Arch. Esp. Urol., 58, 6 (521-530), 2005

\title{
TRASPLANTE RENAL DE DONANTE VIVO: IMPLANTE RENAL Y SUS VARIANTES
}

Rafael G utiérrez del Pozo, David Truán Cacho y Agustín Franco de Castro.

Servicio de Urología. Hospital Clinico de Barcelona. España.

Resumen.- 0 BJETIVO : El objetivo de este trabajo es revisar las diferentes técnicas quirúrgicas que nos permiten realizar un trasplante de riñón de donante vivo.

MÉTODO: Se revisa la literatura y se añade nuestra experiencia en el trasplante de donante vivo.

RESULTADO S: se presentan las diferentes técnicas indicando la que es mas apropiada en cada caso.

CON CLUSIO NES: El trasplante de donante vivo es el que hemos de potenciar si queremos incrementar los trasplantes. Es un trasplante renal complejo ya que no disponemos de parches vasculares y tenemos diferentes técnicas quirúrgicas, pudiendo elegir la que consideremos mejor en cada caso.

Palabras clave: Trasplante. Donante vivo. Técnicas quirúrgicas.
Summary.- O BJEC TIVES: The objective of this paper is to review the various surgical techniques for living donor kidney transplantation.

METHODS: We perform a bibliographic review adding our experience in living. kidney transplantation.

RESULTS: We present various techniques indicating which one is the most appropriate for each case.

CON CLUSIO N S: W e should promote living door kidney transplantation if we want to increase the number of transplants performed. It is a complex transplant because the graft lacks of vascular patches; there are various surgical techniques that we can choose depending on the case.

Keywords: Transplantation. Living donor. Surgical technique.

\section{INTRODUCCIÓN}

La insuficiencia de órganos todavía hoy es el principal factor limitante de los trasplantes, pese al extraordinario trabajo de los equipos de coordinación que consiguen cada año incrementar el número de donantes.

La utilización de órganos procedentes de donantes vivos es una práctica suficientemente antigua. Sólo hay que recordar que los primeros trasplantes de riñón con éxito se consiguieron con riñones pro- 
cedentes de donante vivo. No obstante la polémica, 0 como mínimo el debate, acompaña este tipo de técnica. Se cuestionan aspectos referentes al riesgo de la cirugía del donante y las consecuencias a largo plazo. En la actualidad además se ha incrementado esta posibilidad a otros órganos

El trasplante renal de donante vivo es una practica casi olvidada en nuestro país, aunque algunos equipos no hemos dejado nunca de practicarlo con unos resultados lo suficientemente buenos como para continuar con su realización y potenciación. Por otro lado, en muchos países, entre ellos Estados Unidos, el trasplante de donante vivo cada vez es una práctica más habitual. A sí, no es extraño que en un momento en que los criterios del trasplante se están ampliando día a día y que ésta terapéutica se ofrece a más pacientes, uno piense en el trasplante de donante de vivo como la solución para un determinado grupo de enfermos.

Las ventajas que proporciona el donante vivo son, en primer lugar, el tiempo en que el receptor del órgano procedente de donante vivo permanece en tratamiento de diálisis es menor al que espera un órgano de cadáver; en algunos casos ni tan siquiera es necesario que se someta a dicha terapia, ya que pueden trasplantarse antes.

En segundo lugar también permite una mejor preparación del receptor, así como el poder realizar la intervención de forma programada.

Respecto a los inconvenientes, destacan la morbilidad del donante: la nefrectomía representa un cierto trastorno para el donante y no existe una garantía total de éxito.

\section{Recuerdo histórico:}

La historia de trasplante renal comienza con la cirugía experimental que va a poner a punto la técnica quirúrgica. Se rea lizan trasplantes experimentales en la ingle de perros, realizando las anastomosis vasculares mediante la técnica de Payr, con la utilización tubos de magnesio (1).

Es A lexis Carrel ( 2 ) el que desarrolló la técnica vascular que permitió el impulso de los trasplantes y que consiste en una cuidadosa disección de los vasos, una asepsia rigurosa y el empleo de finas agu- jas curvas y seda impregnada en vaselina, junto con el método de la triangulación y el uso de parches, trabajos por los que recibió el premio Nobel de Medicina en el año 1912.

Voronoy, Y.Y. en 1933 realizó el primer alotrasplante renal humano de donante cadáver (3).

Michon, L. publica en 1953 (4) el primer trasplante de donante vivo, que se realizó en el Hospital $\mathrm{N}$ ecker en 1952 por 0 economos, Vasey y Delinotte (Michon L,1953).

En 1954 Harrison y Murray realizan el primer isotrasplante entre hermanos gemelos, utilizando la misma técnica quirúrgica que hacemos hoy.

El trasplante renal desde entonces ha evolucionado y se han conseguido buenos resultados, siendo actualmente el tratamiento de elección para el insuficiente renal, gracias a los conocimientos inmunológi$\cos$ (HLA - DR) y al descubrimiento de nuevos medicamentos inmunosupresores que evitan o aminoran el rechazo (Azatioprina, Corticoides, Ciclosporina, Suero antilinfocitario, FK-506, Rapamicina, Acido micofenólico etc.)

\section{Características del riñón de donante vivo:}

La primera y mas importante premisa que tiene el cirujano cuando realiza una extracción en un donante vivo, es causar el mínimo daño al donante y correr los mínimos riesgos. Ello conlleva a que la sección de los pedículos vasculares la realicemos de manera suficientemente alejada de los grandes vasos para evitar la posibilidad de que se suelte un clip 0 que se produzcan lesiones en los mismos. Como consecuencia de esta actitud, entendible, nos encontramos que los pedículos vasculares serán cortos y esto condicionará en gran medida la técnica del implante. Si además el equipo que realiza la extracción no es el que participa en el implante, posiblemente la longitud de los vasos sea aún menor.

Independientemente de la técnica de extracción, lo que está claro es que en ningún caso vamos a disponer de parches en los vasos, y que la longitud del pedículo va a ser mas corta que en los injertos procedentes de cadáver.

A la hora de elegir el riñón a extraer seguimos el siguiente razonamiento: en primer lugar el peor 
del donante (quistes, litiasis, menor grosor parenquimatoso, cicatrices renales etc.), en segundo lugar,: el que tenga un pedículo único y en tercer lugar, el riñón izquierdo.

\section{Como tratar los pedículos múltiples:}

Como hemos dicho anteriormente intentamos evitar extraer riñones con pedículo múltiple, pero en ocasiones no lo podemos evitar. En algunos casos porque es el peor riñón del donante y en otros porque durante la extracción nos encontramos vasos polares no detectados por el Angiotac que se realiza sistemáticamente para estudiar el árbol vascular del donante. El objetivo que perseguimos al realizar la cirugía de banco (5) es intentar conseguir el mínimo de vasos a anastomosar al receptor, y esto lo conseguimos anastomosando las polares de forma termino-lateral a la arteria principal, siempre y cuando tengan un diámetro que lo haga posible.

En el caso de pedículos venosos múltiples, si una de las venas representa menos de un $25 \%$ del flujo, la ligamos. Cuando tienen diámetros similares rea lizamos cirugía de banco, teniendo diferentes posibilidades técnicas (5)

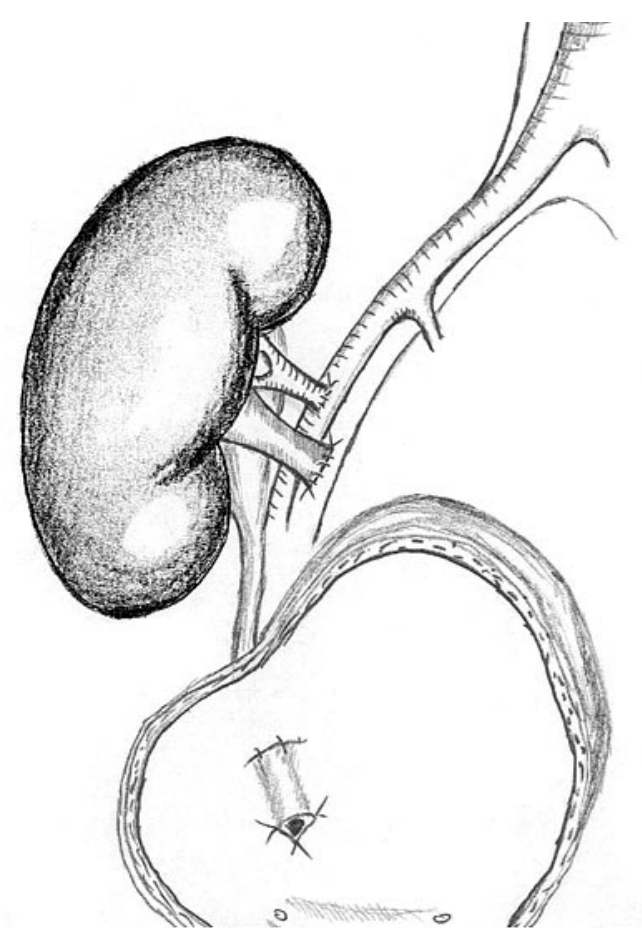

FIG URA 1. Esquema de un trasplante renal hetero tópico con anastomosis vascular a los vasos ilíacos externos y reimplantación ureteral según técnica de Leadbetter-Politano.

\section{TRA SPLANTE REN AL CLASICO} (Trasplante Renal Heterotópico - TRH), (Fig. 1)

La técnica quirúrgica mas utilizada, por ser la mas sencilla, es la colocación del riñón a trasplantar en la fosa ilíaca derecha por vía extraperitoneal.

Se realiza una incisión para-rectal derecha externa en "palo de jockey" que por arriba no sobrepase el ombligo y por abajo llegue hasta la sínfisis del pubis. Se incide la aponeurosis por la línea de Spiegel y se accede al espacio retroperitoneal, seccionando los vasos epigástricos y el ligamento redondo en el mujer, respetando el cordón espermático en el varón.

Se diseca la vena ilíaca externa, ligando los vasos linfáticos con seda. Se coloca el riñón sobre una almohadilla de granizado de hielo y se comienza la anastomosis venosa.

\section{Anastomosis venosa:}

Colocamos un clamp de Satinsky en la vena ilíaca externa totalmente liberada, de tal manera que quede una buena porción de vena por encima de la

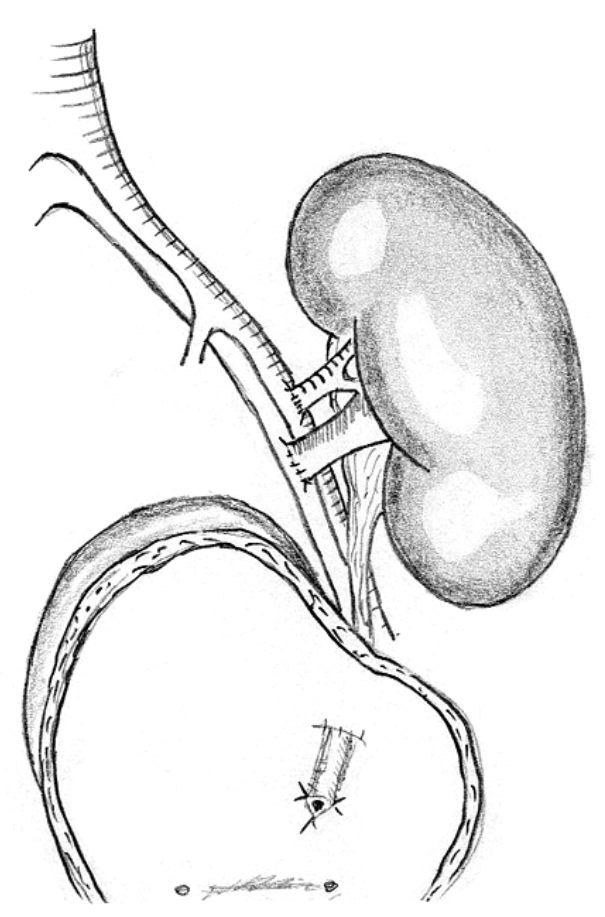

FIG URA 2. Trasplante realizado en fosa iliaca izquier$d a$, con a nastomosis a los vasos ilíacos externos. 
pinza que clampa y realizamos una venotomía con bisturí de punta fina, de la misma longitud que del diámetro de la vena renal. Podemos o no resecar una porción del vaso receptor. Lavamos con heparina para evitar la formación de coágulos e iniciamos la sutura vascular con Prolene ${ }^{\circledR}$ de $6 / 0$, comenzando por un punto en cada extremo de la anastomosis. Suturamos la cara posterior desde dentro y después la cara anterior por fuera, de tal manera que no es necesario movilizar el riñón, que permanece sobre la almohadilla de hielo. Completada la sutura venosa colocamos un clamp de Buldog en la vena renal lo mas próximo al hilio y retiramos el Satinsky, comprobando la estanqueidad de la sutura y al mismo tiempo que liberamos el retorno venoso de la pierna.

\section{Anastomosis arterial :}

En primer lugar seleccionamos el lugar de la arteria donde vamos a realizar la anastomosis, que solemos situar en la ilíaca externa, por ser el lugar donde existen menos placas de ateroma, lo que comprobamos por palpación. La anastomosis la solemos hacer de forma termino-lateral. Procuramos que el lugar elegido nos permita realizar una anastomosis fácil, sin que se produzcan acodaduras en la arteria renal. Primero procedemos a la ligadura de los vasos linfáticos que transcurren por el lugar elegido para la anastomosis, liberando el mínimo imprescindible. Seguidamente, pasamos una tijera curva por debajo de la arteria, lo que nos permite elevarla para colocar el clamp de Satinsky; si existiera mucha ateromatosis, clamparemos la arteria en los lugares donde no existan placas con clamps rectos. Realizamos una arteriotomiía con bisturí de punta fina y casi siempre resecamos un porción arterial, lo que nos facilitará la anastomosis y disminuirá la posibilidad de estenosis. Realizamos una sutura con Prolene ${ }^{\circledR}$ de $6 / 0$ de forma continua (360 grados), siempre que el calibre de la arteria lo permita. De lo contrario realizamos la sutura con puntos sueltos. Comprobamos la estanqueidad de la sutura desclampando la arteria ilíaca. Se retira el buldog de la vena renal y se revisa la hemostasia antes de proceder a la anastomosis de la vía urinaria.

\section{Anastomosis ureteral:}

Para restablecer la continuidad de la vía urinaria se han descrito numerosas técnicas, pero las comúnmente utilizadas son las anastomosis ureterovesicales de las cuales existen también multitud de variantes, resumiéndose en dos: técnicas transvesicales y extravesicales.
Hay defensores para cualquier técnica, justificándose unas y otras por la facilidad de las mismas, la rapidez y fundamentalmente por los resultados (índices bajos de estenosis y de fístulas).

Describiremos la técnica transvesical con túnel submucoso que hemos utilizado en mas de 2500 trasplantes con excelentes resultados. Es la descrita por Politano-Leadbetter en 1958 (6).

Para localizar la vejiga, la distendemos introduciendo suero fisiológico a través de una sonda vesical colocada previamente. Realizamos con bisturí eléctrico una cistotomía transversa en la cara lateral derecha vesical, colocando en cada ángulo un punto fiador que después utilizaremos para cerrarla. Labramos un túnel submucoso de a proximadamente $3 \mathrm{~cm}$ de longitud que termina cerca del trígono, por el que haremos pasar el uréter, el cual hemos introducido previamente en la vejiga ayudados por un disector que atraviesa la pared vesical. Procuramos no dejar el uréter demasiado largo. Lo espatulamos en su extremo distal y lo anclamos a la vejiga con tres puntos de material reabsorvible (habitualmente Monocryl $₫ 6 / 0$ ), cerrando seguidamente la mucosa del neohiato. El último paso consiste en cerrar la cistotomía en dos planos con sutura reabsorvible. (M onocryl® $3 / 0$ )

\section{Trasplante Renal en posición lumbar baja: (Fig. 2)}

Es la técnica preconizada por Gil-Vernet (7), en la que se anastomosa la vena renal a la vena cava o inicio de la vena iliaca primitiva y la arteria renal a la arteria ilíaca primitiva, pudiendo ser de utilidad en el caso de disponer de una vena renal muy corta, y teniendo el inconveniente de que necesitamos trasplantar un uréter mas largo, además de que la arteria ilíaca primitiva suele estar afecta con mas frecuencia de ateromatosis en este lugar. Es una técnica actualmente en desuso, sustituida por la anastomosis a los vasos ilíacos externos, pero constituye un recurso en algunos casos.

\section{Trasplante Renal en fosa ilíaca izquierda (Trasplante renal ortotópico - TRO), (Fig. 3 )}

Durante mucho años colocamos los riñones derechos en la fosa ilíaca izquierda con la finalidad de disponer la vía urinaria siempre en situación anterior para que nos resultaran mas fácil las reintervenciones 
sobre la misma (resolución de fístulas, estenosis etc.). Pasamos después a colocarlos todos los primeros en fosa ilíaca derecha, pero invertíamos los riñones derechos con la misma finalidad, dando lugar a una patología, que se llegó a conocer como la del riñón invertido, fundamentalmente ocasionado por dificultades de vaciado del injerto.

A ctualmente colocamos los riñones en fosa ilíaca izquierda cuando está ocupada la derecha, o cuando existe una patología habitualmente vascular, que lo contraindique.

Esta variante difiere fundamenta Imente en que habitualmente necesitamos una vena renal más larga, y que en el caso de disponer de un riñón derecho en muchas ocasiones puede resultar dificultosa la anastomosis venosa.

\section{Trasplante Renal ortotópico izquierdo: (Fig. 4).}

El primer trasplante renal ortotópico fue publicado por Lowler en 1950 (8).

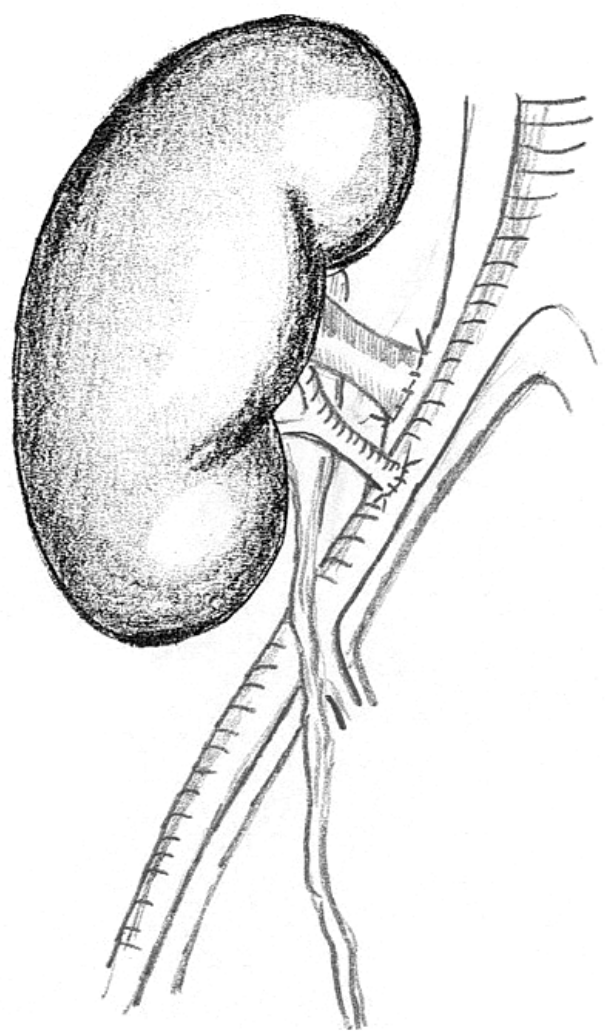

FIG URA 3. Trasplante renal en fosa lumbar baja, con a nastomosis a los vasos ilíacos primitivos.
Gil-Vernet en 1978 describe una vía de abordaje extraperitoneal a los vasos esplénicos por lumbotomía, utilizada inicialmente para la revascularización espleno renal en la estenosis de la arteria renal, después para la derivación esplenorenal en la hipertensión portal y mas tarde en el trasplante renal $(9,10)$.

El abordaje se realiza a través de una lumbotomía izquierda con resección de la 12 a costilla. Rechazamos el riñón hacia la línea media y ligamos y seccionamos la arteria renal. Se diseca la vena renal con mucho cuidado ligando todas sus colaterales hasta su bifurcación muy intrasinusal con la finalidad de que sea lo mas larga posible. La pelvis renal la disecamos también muy intrasinusal, seccionandola por sus infundíbulos, respetando los mas posible el tejido peripiélico. Localizamos la arteria esplénica en la cola del páncreas, habitualmente por palpación y la liberamos ligando sus colaterales, hasta su bifurcación, donde la seccionamos previa ligadura de las mismas.

La anastomosis venosa la realizamos de forma termino-terminal entre la vena renal del injerto y la vena renal del receptor, con dos suturas continuas de180․

La anastomosis arterial se realiza entre la arteria esplénica del receptor y la arteria renal del

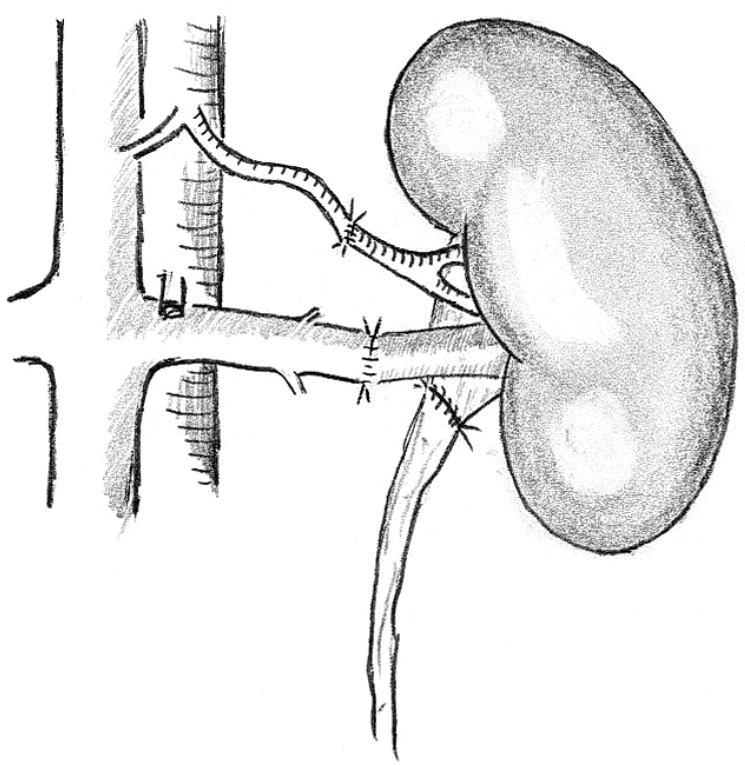

FIG URA 4. Trasplante renal ortotópico izquierdo, con anastomosis de la vena renal a la venal renal del receptor y la arteria a la arteria esplénica. 
injerto de forma termino-terminal, previa espatulación de ambas bocas y con puntos sueltos para evitar estenosis posteriores.

La vía urinaria se restablece mediante una anastomosis pielo-piélica entre la pelvis del receptor y la pelvis del injerto, con dos suturas continuas de180ํ․ dejando tutorizada la vía con un catéter doble J o una nefrostomía mínima (tipo Gil-Vernet) caso de no poder colocar el doble-J de forma retrógrada.

\section{Trasplante Renal ortotópico izquierdo a vena espléni- ca. (Fig. 5).}

Es una técnica de recurso cuando nos encontremos, al realizar un trasplante ortotópico, que la vena renal no es viable, habitualmente porque existe una malformación, y encontramos varias venas pequeñas unidas entre sí que no tienen una luz suficiente para que nos permita su anastomosis a la vena renal. En alguna ocasión podemos incluso encontrarnos con un ovillo venoso de paredes muy finas por ejemplo en las agenesias de cava inferior, por suerte poco frecuentes.

En estos casos podemos anastomosar la vena renal a la vena esplénica (11) tanto en termino terminal como termino-lateral, sin necesidad de realizar una esplenectomía.

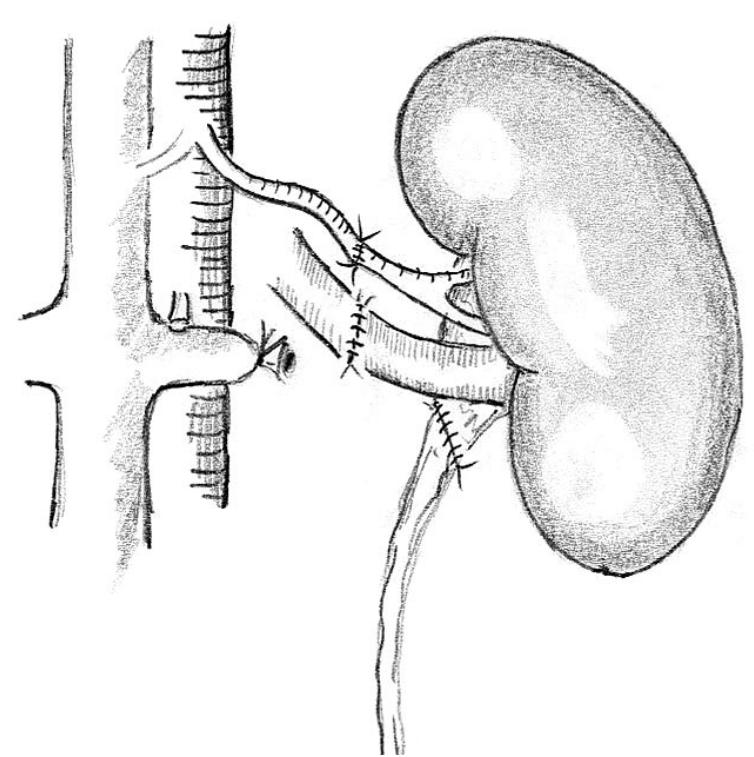

FIG URA 5. Trasplante renal ortotópico izquierdo, con anastomosis de la vena renal a la circulación portal (vena esplénica).

\section{Trasplante Renal ortotópico derecho:}

En el trasplante ortotópico utilizaremos la vena renal del receptor y la arteria la anastomosaremos a la arteria hepática propia.

Nosotros tenemos un caso de trasplante renal ortotópico derecho en el que utilizamos la arteria renal del receptor que mantenía su calibre por ser la que alimentaba una fístula arteriovenosa. (Figuras 6 y 7).

\section{Trasplante Renal aorto-cavo:}

Es utilizado fundamentalmente en pediatría, en niños por debajo de los $20 \mathrm{~kg}$, situándose el injerto en la cavidad peritoneal a través de una incisión media 0 pararrectal y anastomosando la vena renal a la vena cava y la arteria renal a la aorta. Se procura que ésta se realice con puntos sueltos con la finalidad de que la boca anastomótica crezca con el niño.

La elección de dónde colocar el riñón la determinará la concordancia o discrepancia de tamaño que exista entre el donante y el receptor, y el éxito del mismo va a depender de varios factores: tamaño del injerto en relación al receptor, colocarlo de forma intraperitoneal cuando sea necesario, evitar la necrosis tubular y fundamentalmente tener mucho cuidado con el manejo intraoperatorio de los líquidos. (12)

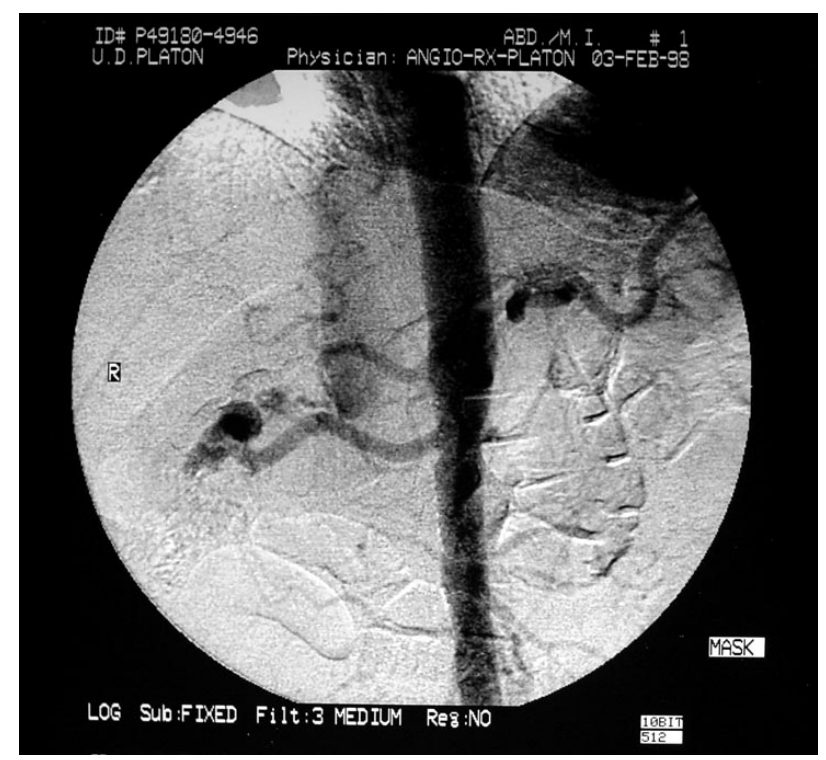

FIG URA 6. Arteriografía que muestra una fístula arteriovenosa renal derecha, lo que hace que se mantenga la arteria renal con un calibre adecuado. 


\section{Trasplante Renal a derivaciones urinarias:}

La incidencia de pacientes candidatos a trasplante renal que tienen 0 una enterocistoplastia de aumento o una derivación urinaria realizada bien por patología congénita o tumoral, ha aumentado considerablemente. Repasaremos nuestra actitud ante los diferentes supuestos:

- Microvejiga escleroatrófica en candidato a TR: Se debe realizar una plastia de agrandamiento (cuando exista un cuello vesical y una uretra aptas para la continencia) o bien una derivación urinaria previa al trasplante, aunque hay quien lo aconseja durante el trasplante (13). El realizarla antes tiene el inconveniente, si se encuentra en situación de oliguria 0 anuria, de que se han de realizar diariamente cateterismos e irrigaciones con suero salino y antibiótico con el fin de evacuar las secreciones intestinales, evitando las infecciones (piocisto) y tratando de mantener un volumen vesical a decuado.

El realizarla durante el TR, al estar el paciente inmunodeprimido, aumenta las probabilidades de complicaciones fundamentalmente sépticas (infeccio-

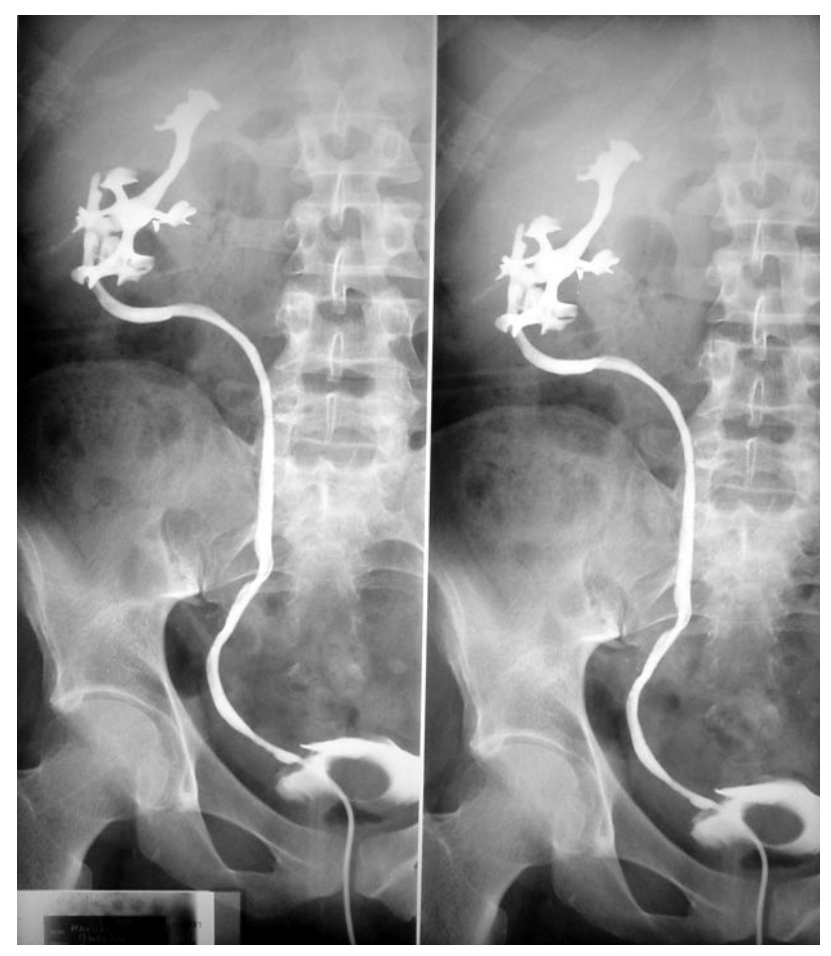

FIG URA 7. Pielografía ascendente de un riñón trasplantado de forma ortotópica derecha. nes y fístulas...). Los segmentos intestinales que pueden ser utilizados tanto para la ampliación vesical (iliocistoplastia, colocistoplastia) como para realizar una derivación urinaria son muy variados así como las técnicas quirúrgicas empleadas (Derivaciones urinarias incontinentes: Bricker. Derivaciones urinarias continentes: Kock, Mainz, Indiana. Derivaciones ortotópicas continentes: Studer, Padovana, Haudpman, Doble W etc.)

- Pacientes con una derivación urinaria:

1. Ureterostomía cutánea: Las ureterostomías cutáneas previas a la entrada en insuficiencia renal suelen presentar uréteres dilatados y pueden ser utili-

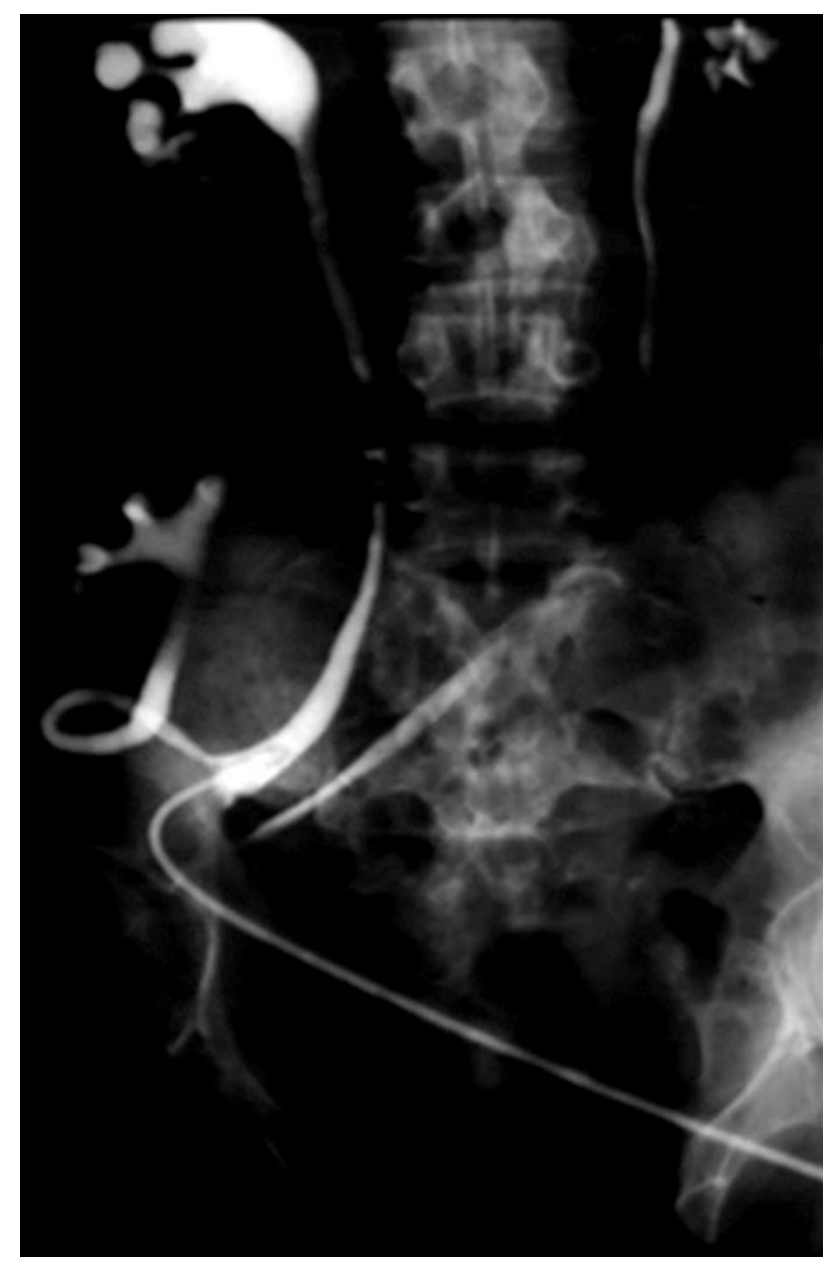

FIG URA 8. Pielografía retrógrada a través de ureterostomía cutánea, donde se observa la vía urinaria de trasplante colocado en fosa ilíaca derecha y el uréter anastomosado de forma termino-lateral a la ureterostomía cutánea. 
zados como derivación conducto para el riñón trasplantado, aunque hay trabajos que indican que se ha de realizar nefrectomía previa y resección de parte del uréter, utilizando la última porción de la ureterostomía unida a la piel (14). Nosotros hemos realizado una anastomosis termino lateral al uréter de una ureterostomía cutánea en un paciente afecto de una extrofia vesical colocando el riñón en FID (Figura 8 ).

2. Conducto ileal (Bricker): Si se dispone de un asa de Bricker se puede realizar un TRO y utilizar el uréter del receptor, haciendo una anastomosis pielopiélica, (15) o anastomosando el uréter del riñón trasplantado, de forma terminolateral, al asa ileal, si es posible de forma extraperitoneal, aunque quedará el riñón más bajo y por ello tendrá un peor comportamiento urodinámico y un mayor número de complicaciones. Así que en lo posible hemos de procurar colo-

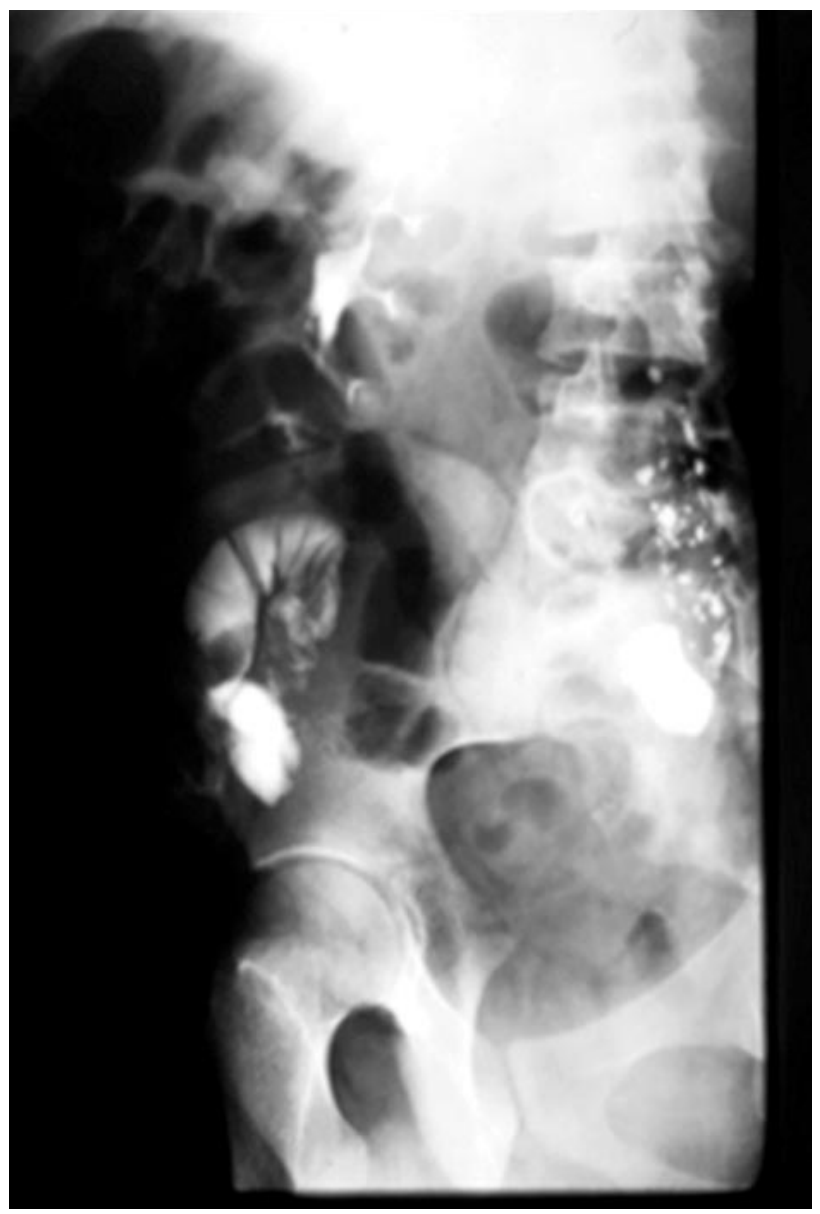

FIG URA 9. Trasplante renal ortotópico, donde se ha anastomosado el uréter a un conducto ileal lasa de Bricker). car el riñón por encima del asa ileal. (Figura 9) El mismo razonamiento sirve para las derivaciones continentes.

3. Ureterosigmoidostomía: Si nos encontramos un paciente con una ureterosigmoidostomía, no somos partidarios de utilizar este tipo de derivación en el TR, por lo que procederíamos a realizar un asa de Bricker antes de introducir al paciente en lista de espera o bien realizarlo en el mismo acto del TR. No tenemos experiencia al respecto.

4. Enterocistoplastías: Se utiliza con mayor frecuencia el íleon terminal y el colon sigmoide. El trasplante renal se puede realizar en cualquier fosa iliaca y anastomosando el uréter habitua Imente sin túnel submucoso directamente al intestino utilizado, aunque si no existe afectación ureteral también pueden ser éstos utilizados. Las principales complicaciones de las plastias de aumento son las infecciones urinarias, pudiendo precisar el autocaterismo.

5. El mismo razonamiento puede ser utilizado para las derivaciones urinarias ortotópicas continentes.

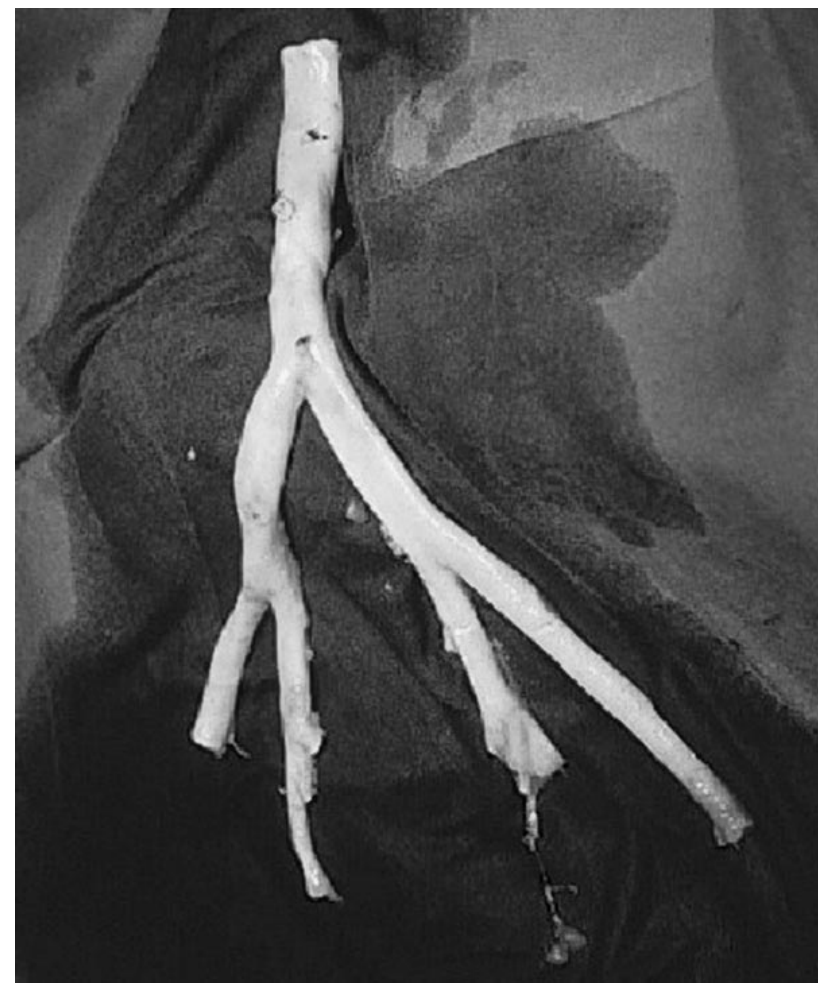

FIG URA 10. Injerto aortoilíaco criopreservado. 
- Trasplante renal en receptores con patología aortoilíaca:

La asociación entre enfermedad renal terminal y enfermedad arterial oclusiva cada día es mas frecuente. La edad media de los pacientes en hemodiálisis se ha incrementado. Ello supone una prevalencia mayor de enfermedad vascular, a lo que contribuye el considerable número de pacientes con diabetes mellitus, HTA, tabaquismo, hipercolesterolemia etc.

Por otro lado es conocido que la insuficiencia renal crónica avanzada se asocia con enfermedad arterial "per se", lo que también se produce en los pacientes en hemodiálisis y generalmente con un patrón diferente (16) (arteriopatía oclusiva acelerada, extensa, con importante y frecuente calcificación parietal). Este incremento de la edad hace que exista también una mayor frecuencia de aneurismas de aorta abdominal en pacientes candidatos a un trasplante renal o ya trasplantados. A ello ha contribuido el incremento considerable en la expectativa de vida del trasplantado renal y es previsible que la prevalencia de enfermedad arterial oclusiva o aneurismática en este grupo de pacientes se incremente en el futuro. La patología aortoilíaca la podemos dividir en: enfermedad arterial oclusiva y aneurismática.

El tratamiento de la patología aortoilíaca puede ser: mediante prótesis a ortobifemoral, endarterectomia localizada y angioplastia percutánea, con 0 $\sin$ "sten"

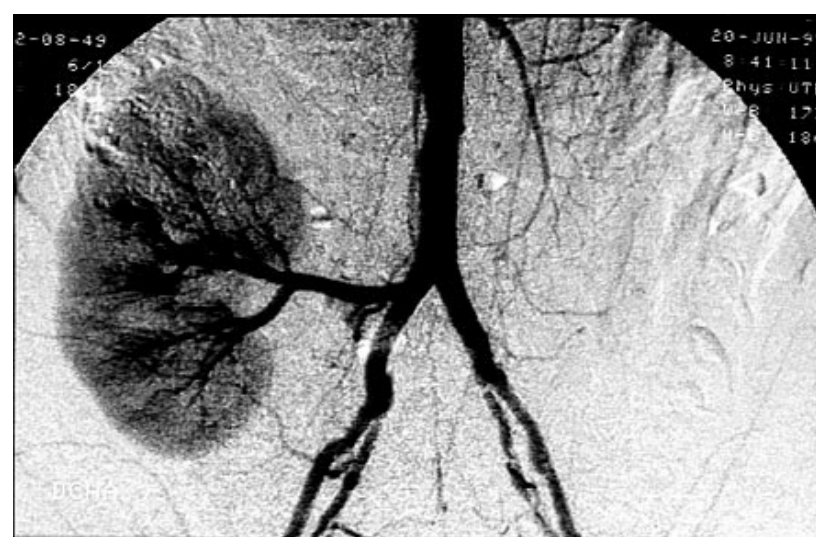

FIG URA 11. Arteriografía de trasplante de donante vivo en fosa ilíaca derecha, sobre injerto aorto-ilíaco criopreservado.
En la cirugía de la patología aortoilíaca respecto al TR se puede realizar:

- cirugía secuencial (previa o posterior)

- cirugía simultánea

Trasplante renal sobre prótesis aortoilíaca previa: $(17,18)$. Se caracteriza por:

1. Mayor dificultad por fibrosis periprotésica, especialmente la disección de la vena ilíaca.

2. Tasa de pérdidas de injertos en el postoperatorio similares.

3. No existe mayor riesgo de mortalidad.

4. No existe mayor riesgo de infección de la prótesisprótesis.

5. No existe mayor riesgo de estenosis arteriales tardías.

6. Menor supervivencia a 5 años.

\section{Cirugía simultánea: (19) Se caracteriza por:}

1. Menor dificultad técnica.

2. Manejo hidroelectrolítico más sencillo.

3. Una sola intervención (reduce riesgos, estancias, costes).

\section{Trasplante renal y sustitución aortoilíaca simultánea}

En el supuesto de que el receptor tenga una patología a ortoilíaca severa bien sea oclusiva o aneurismática, si disponemos de un donante vivo es el caso ideal para realizar las dos intervenciones a la vez, pudiendo recurrir a la sustitución por una prótesis (20) o por un injerto criopreservado (21) ( Figuras 10 y 11)

\section{PATOLOGIA VENOSA}

- Agenesia de la vena cava inferior: es una patología congénita poco frecuente, que a veces se asocia a una hipoplasia renal. Generalmente no se sospecha su presencia y salvo complicaciones, estos pacientes no suelen presentar signos clínicos de la a nomalía vascular, como varices, circulación colateral, etc. El diagnóstico se suele hacer con posterioridad a la imposibilidad de poder anastomosar la vena renal a los vasos ilíacos. La opción quirúrgica es realizar un trasplante renal ortotópico anastomosando la vena renal a la vena esplénica. (11) 
- Trombosis iliocava: el enlentecimiento de la circulación y el traumatismo de la pared venosa, además de la alteración de los mecanismos de la coagulación son los factores capaces de producir una flebotrombosis, estando contraindicado realizar en estos casos el TR en las fosas iliacas, a unque una ilíaca estuviera libre, ya que ésta actúa como vía de drenaje colateral de la pierna afectada y el clampaje de la misma puede favorecer la aparición de más trombosis. En estos casos creemos indicado el TRO anastomosando la vena renal a la vena renal del receptor, si ésta no está afectada por la trombosis, y si lo estuviera, la anastomosaríamos a la vena esplénica. Existen otras técnicas como la descrita por Rosenthal y Loo (22) donde anastomosan la vena renal en TL a la vena mesentérica y la arteria renal a la aorta. 0 tra alternativa es la de Gibel (23) que invierte el riñón y emplea toda la vena cava infrarrenal y una de las ramas de la ilíaca para sortear la zona afecta por la trombosis.

\section{BIBUOGRAFIA}

1. PAYR, E.: "Beiträge zur technik der blutgefässe und nervennaht nebst mitteilunge ubre die verwendung eines resorbiebaren metallen in der chirurgie". Arch. Klin. Chir., 62: 67, 1900.

2. CARREL, A.: "Anastomosis and transplantation of blood vessels". Ann. Med., 10: 284, 1905.

3. HAMILTON, D.N.H.; REID, W.A.; YU, Y.: "Voronoy and the first human kidney allograft". Surg. Gynecv. Obst., 159: 289, 1984.

4. MICHON, L.; HAMBURGER, J.M.; OECONOMOS, N. y cols.: "Une tentative de transplantation renale chez 1'homme. Aspects médicaux et biologiques". Presse Med., 61: 1419, 1953.

5. TALBOT-WRIGHT, R.: "Cirugía de Banco". pp: 6594 en Manual de cirugía del trasplante renal. R. TalbotWright. Y P. Carretero. Editorial médica panamericana 1995.

6. POLITANO, V.A.; LEADBETTER, W.F.: "An operative technique for the correction of vesico-ureteric reflux". J. Urol., 79: 932, 1958.

7. GIL-VERNET, J.M.: "Cirugía del trasplante renal". pp: 175-191, en Trasplante renal. Caralps A., GilVernet JM. y Vives J. Eds. Toray S.A., Barcelona, 1983.

8. LOWLER, R.H.; WEST, J.W.; McNULTY, P.H. y cols.: "Homotrasplantation of the kidney in the human". JAMA, 144: 844, 1950.
9. GIL-VERNET, J.M.; CARALPS, A.; RUANO, D.: "New approach to the splenic vessels". J. Urol., 119: 313, 1978.

10. GIL-VERNET, J.M.; TALBOT-WRIGHT, R.; CARRETERO, P. y cols.: "Trasplante renal ortotópico y resultados de 139 consecutivos". Cir. Esp., 3: 310, 1989.

11. TALBOT-WRIGHT, R.; FIGULS, J.; GELABERT, A. y cols.: "Alternative surgery in renal transplantation: spleno-renal anastomosis". Eur. Urol., 8: 127, 1982.

12. ROSENTHAL, J.T.; ETTENGER, R.B.; EHRLICH, R.M. y cols.: "Technical factors contributing to successful kidney transplantation in small children”. J. Urol., 144: 116, 1990.

13. KIM, C.O. Jr.; GOSALBEZ, R. Jr.; BURKE, G.W.III.: "Simultaneous ureteropcystoplasty and living related renal transplantation”. Clin. Transplantation, 10: 333, 1996.

14. CORREAS GÓMEZ, M.A.; PORTILLO MARTÍN, J.A.; GUTIÉRREZ BAÑOS, J.L. y cols.: "Dérivation urinaire extravesical en transplantation rénale". J. d’Urologie (París), 99 : 255, 1993.

15. ALCARAZ, A.; TALBOT-WRIGHT, R.; OPPENHEIMER, F. y cols.: "Surgical alternatives in renal transplantation with unavailability of the lower urinary tract". Trasplant. Proc., 24: 1876, 1992.

16. LINDNER, A.; CHARRA, B.; SHERRARD, D.J. y cols.: "Accelerated arteriosclerosis in prolonged maintenance of haemodialysis". New Eng. J. Med., 290: 697, 1974.

17. VAN DER VLIET, J.A.; NAAFS, D.B.J.; VAN BOCKEL, J.H. y cols.: "Fate of renal allografts connected to a vascular prostheses". Clin. Transplantation, 10: 199, 1996.

18. WRIGHT, J.G.; RESI, R.J.; MASSOP, D.W. y cols.: "Safety of simultaneous aortic reconstruction and renal transplantation”. Am. J. Surg., 162: 126, 1991.

19. PITTALUGA, P.; HASSEN-KHODJA, R.; CASSUTO-VIGUIER, E. y cols.: "Aortoiliac reconstruction and kidney transplantation: a multicenter study". Ann. Vac. Surg., 12: 529, 1998.

20. TALBOT-WRIGHT, R.; MASTRES, C.A.; CAMPISTOL, J.M. y cols.: "Simultaneous aortic bifurcation graft and Kidney transplantation from the same multiorgan donor: a new therapeutic tool in complex renal transplantation”. J. Urol., 156: 2000, 1996.

21. MESTRES, C.A.; TALBOT-WRIGHT, R.; CARRETERO, P.: "Simultaneous aortorenal homograft transplantation: expanding the indications for renal and vascular replacement". Br. J. Surg., 83: 918, 1996.

22. ROSENTHAL, J.T.; LOO, R.K.: "Portal venous drainage for cadaveric renal transplantation". J. Urol., 144: 237, 1991.

23. GIBEL, L.J.; CHAKERIAN, M.; HARFORD, A. y cols.: "Transplantation using inverted renal unit and donor vena cava-iliac vein conduit to bypass recipient distal vena cava and iliac venous system". J. Urol., 140: $1480,1988$. 